Review Article

\title{
Impact of COVID- I9 Pandemic on Mental Health Care Delivery: A Narrative Review
}

\author{
Binil V', Divya KY ${ }^{2}$
}

${ }^{1}$ Associate Professor, Manipal College of Nursing, Manipal Academy of Higher Education, Manipal, India.

${ }^{2}$ Lecturer, College of Nursing, Sultan Qaboos University, Al Khoud, Muscat 123, Sultanate of Oman.

DOI: https://doi.org/10.24321/0019.5138.202115

\section{I $\quad \mathbf{N} \quad \mathbf{F} \quad \mathbf{O}$}

\section{Corresponding Author:}

Divya KY, College of Nursing, Sultan Qaboos University, Al Khoud, Muscat 123, Sultanate of Oman.

E-mail Id:

kydivyam@gmail.com

\section{Orcid Id:}

https://orcid.org/0000-0003-0801-2682

How to cite this article:

Binil V, Divya KY. Impact of COVID-19 Pandemic on Mental Health Care Delivery: A Narrative Review.

J Commun Dis 2021; 53(1): 89-95.

Date of Submission: 2020-12-16

Date of Acceptance: 2021-03-10

\section{$\begin{array}{llllllll}\mathbf{A} & \mathbf{B} & \mathbf{S} & \mathbf{T} & \mathbf{R} & \mathbf{A} & \mathbf{C} & \mathbf{T}\end{array}$}

Background: Mental health care professionals across the globe should be prepared to contain the spread of COVID-19 among clients with mental illness and should adopt appropriate strategies to manage them effectively.

Objective: The objective of this review was to summarize the impact of COVID-19 pandemic on mental health delivery.

Methods: A comprehensive literature search was done to identify the effect of COVID-19 global pandemic in mental health delivery. Articles addressing mental health concerns of COVID-19 and its impact on preexisting mental illness and mental health care delivery, available free download in English language were included. A total of nine primary studies published from the onset of COVID-19 until 15th July 2020 were referred to prepare this narrative review.

Result: There is evidence that patients with preexisting mental illnesses shows increase in stress, anxiety, sleep disturbances and COVID-19 related delusions and hallucinations during this global pandemic. The proposed drug treatment for COVID-19 and the imposed restrictions on the public to prevent the spread of the disease had resulted in exacerbation of existing mental illness or triggered new mental illness.

Conclusion: There should be more research coming up to understand the real effect of COVID-19 on mental health care delivery and possible alternatives to global mental health delivery at the time of global pandemic.

Keywords: COVID-19, Mental Health Care, Pandemic, Impact on Mental Health

\section{Introduction}

COVID-19 is an ongoing global pandemic caused by SARS CoV-2. As of December 09,2020 COVID-19 has infected 68.2 million cases globally with 1.56 million deaths and 44 million recoveries. ${ }^{1}$ However, COVID-19 pandemic is considered to be a physical health calamity, it has its seeds for a major mental health calamity as well. As we all know, one of the most neglected areas of health is mental health despite its impact on the individuals, families and society. ${ }^{2}$ This might be due to poor prognosis of mental illness and the stigma associated.

We are witnessing an impending mental health crisis with 
social isolation, unemployment, stress of the pandemic itself and shut down of face-to-face mental health consultation services across the country for the people who are already availing mental health treatment. People with substance abuse and other Pre-existing Mental Illnesses (PMI) are experiencing disruption to their treatment, counselling services and rehabilitation activities because of this pandemic. ${ }^{3}$

According to World Health Organization (WHO), before the occurrence of COVID-19 outbreak, almost two-thirds of people with a known psychiatric disorder never asked for help from a health professional owing to stigma, discrimination and neglect associated with psychiatric disorders. The WHO face sheet also mentioned that 76$85 \%$ of people with mental disorders receive no treatment or receive poor quality care for their disorder especially in low- and middle-income countries. ${ }^{4}$

\section{Significance of the Review}

Patients in mental health care unit are more vulnerable to COVID-19 pandemic than in other units due to various reasons. The structural aspects of psychiatric hospitals like close proximity of the beds, high density of patients in each unit, lack of isolation areas, closure of mental health community facilities, poorly trained mental health staff to face infectious diseases all increases the risk of COVID-19. People with preexisting mental illness may have difficulty in following the pandemic prevention regulations like use of masks, frequent hand hygiene and social distancing due to their poor insight and or perception and thought disturbances. Moreover, social isolation may precipitate another episode of depression, obsessive-compulsive disorder, and schizophrenia or substance use disorders. Treatment of COVID-19 in people with PMI using various drugs is also known to precipitate psychosis like symptoms. The possible lack of resources and preparedness for pandemic mandates a thorough understanding of the effect of COVID-19 on pre-existing mental illness. To understand the impact of COVID-19 and possible future directions in improving the treatment of pre-existing mental illness, a literature search on the available evidence is done from the onset of COVID-19 until $15^{\text {th }}$ August 2020 and is summarized in a narrative form.

\section{Methods}

A comprehensive literature search were done in PubMed, Science direct, EMBASE, Web of Science, Scopus, and CINAHL to identify the impact of COVID-19 on pre-existing mental illness. The search terms used were mental illness and COVID-19, schizophrenia and COVID-19, anxiety and COVID-19, depression and COVID-19, substance abuse and COVID-19, ADHD and COVID-19, autism and COVID-19, elderly and COVID-19. The selection criteria include articles addressing mental health concerns of COVID-19 and its impact on preexisting mental illness and their treatment, available in English for free download in the institutional health science library, where the researchers work. The both researchers identified 28 articles independently (14 each), after removing 8 duplicates, 20 articles were included for title and abstract screening. Eleven articles were further eliminated either due to lack of information, full text not available in English, or not addressing preexisting mental illness. Finally, nine primary studies published from the onset of COVID-19 until 15 $5^{\text {th }}$ October 2020 were referred to prepare this narrative review. Three case reports, one case control study, one retrospective study, one preliminary naturalistic study, one cross sectional study and two survey were analyzed to understand the effect of COVID-19 on clients with mental illness. The studies were from various geographic locations like Germany (2), China (2), United Kingdom (1) Spain (1), Italy (1), United States-Canada (1) and Australia (1). As only a handful of articles addressing the impact of COVID-19 on preexisting mental illnesses were available from the onset of COVID-19 until August2020, no specific quality assessment tool was used by the researchers. However, articles not meeting the inclusion/exclusion criteria were excluded. In addition, the included articles were addressing impact of COVID-19 on various preexisting mental illnesses; hence, a narrative review is done and presented here.

\section{Result \& Discussion}

The search results revealed little evidence on COVID-19 and effect on already existing mental illness and treatment specific to any region or country. Hence, overall themes are identified from the published articles and presented. More region wise and disease specific research is essential to understand its real impact on pre-existing mental illness.

Table 1, shows the impact of COVID-19 on clients with preexisting mental illnesses. Clients with psychosis have developed COVID-19 related content in their delusions and hallucinations 8 and there is moderate to severe insomnia ${ }^{33,34,37}$ and PTSD, anxiety and depression, ${ }^{34,36}$ among COVID-19 positive cases with mental illnesses. It has also observed that there is a risk for physical consequence like allergic dermatitis and chemical conjunctivitis due to over involvement in hygienic activities or poor understanding of COVID-19 related restrictions. ${ }^{33}$ It has also shown that there is an increased risk of clozapine toxicity in patients with COVID-19 infections due to downregulation of clozapine metabolism. ${ }^{37}$ The obsessions and compulsions are increased during the quarantine period for people with already existing obsessive compulsive disorders. ${ }^{38}$ People with preexisting anxiety disorders have more COVID-19 related stress than people with mood disorders or the general population itself. ${ }^{39}$ There is a significant increase in the psychological distress and COVID-19 related life style changes in people with mood disorder as compared to general population. ${ }^{40}$ 
Table I.Impact of COVID-19 on mental illness

\begin{tabular}{|c|c|c|c|c|c|}
\hline Study ID & Study design & Country & \begin{tabular}{|c} 
Sample \\
size
\end{tabular} & $\begin{array}{c}\text { Psychiatric } \\
\text { diagnosis }\end{array}$ & Impact \\
\hline $\begin{array}{l}\text { Fischer M, } \\
\text { et al. }{ }^{8}\end{array}$ & Case report & Germany & 1 & $\begin{array}{l}\text { Known case of } \\
\text { Schizophrenia } \\
\text { from } 2011 \\
\end{array}$ & $\begin{array}{l}\text { COVID-19 related delusions (his parents } \\
\text { and neighbors being infected with } \\
\text { COVID-19) and hallucinations }\end{array}$ \\
\hline $\begin{array}{c}\text { Jessenia } \\
\text { MG, et al. }{ }^{33}\end{array}$ & Case report & Spain & 1 & $\begin{array}{l}\text { Schizophrenia } \\
\text { with alcohol and } \\
\text { cannabis abuse }\end{array}$ & $\begin{array}{l}\text { Delusion of being infected with COVID-19 } \\
\text { from last week of April 2020. Overuse } \\
\text { of cleaning products resulted in contact } \\
\text { dermatitis and chemical conjunctivitis }\end{array}$ \\
\hline $\begin{array}{l}\text { Hao F, et } \\
\text { al. }^{34}\end{array}$ & $\begin{array}{l}\text { Case control } \\
\text { study }\end{array}$ & China & $\begin{array}{l}76 \\
\text { Cases } \\
\& \\
109 \\
\text { Control }\end{array}$ & $\begin{array}{l}\text { Diagnosis not } \\
\text { specified }\end{array}$ & $\begin{array}{l}\text { Psychiatric patients were displaying } \\
\text { higher scores of PTSDs, stress, anxiety, } \\
\text { depression, insomnia, uncertainties about } \\
\text { physical health, annoyance, irritability and } \\
\text { suicidal ideation as compared to controls } \\
\text { who are healthy and COVID-19 negative }\end{array}$ \\
\hline $\begin{array}{l}\text { Schützwohl } \\
\text { M, et } \\
\text { al. }{ }^{35} \text { (Pre } \\
\text { published) }\end{array}$ & Survey & Germany & 132 & $\begin{array}{l}\text { Chronic mental } \\
\text { illness, Acute } \\
\text { mental illness } \\
\text { and General } \\
\text { population } \\
\end{array}$ & $\begin{array}{l}\text { All groups experienced no significant } \\
\text { impairments in their social participation } \\
\text { during the lockdown restrictions, showing } \\
\text { themselves to be highly resilient to the } \\
\text { coronavirus pandemic }\end{array}$ \\
\hline Liu X, et al. ${ }^{36}$ & $\begin{array}{c}\text { Retrospective } \\
\text { double-centre } \\
\text { study }\end{array}$ & China & 51 & $\begin{array}{c}30 \\
\text { schizophrenics } \\
\text { without } \\
\text { COVID-19 } \\
\text { And } 21 \\
\text { schizophrenics, } \\
\text { in the COVID-19 } \\
\text { suspected group }\end{array}$ & $\begin{array}{l}\text { Significantly higher levels of depression, } \\
\text { anxiety and poorer sleep quality among } \\
\text { patients with suspected COVID-19 } \\
\text { cases as compared to negative cases of } \\
\text { COVID-19 }\end{array}$ \\
\hline $\begin{array}{c}\text { Cranshaw T, } \\
\text { et al. }{ }^{37}\end{array}$ & Case report & $\begin{array}{c}\text { United } \\
\text { Kingdom }\end{array}$ & 1 & $\begin{array}{l}\text { Organic } \\
\text { psychosis } \\
\text { (treated with } \\
\text { clozapine) }\end{array}$ & $\begin{array}{l}\text { COVID-19 infection result in increased } \\
\text { risk of pneumonia, clozapine toxicity and } \\
\text { disruption to clozapine treatment due to } \\
\text { COVID-19 induced lymphopenia }\end{array}$ \\
\hline $\begin{array}{c}\text { Davide } P \text {, et } \\
\text { al. }^{38}\end{array}$ & $\begin{array}{l}\text { Preliminary } \\
\text { naturalistic } \\
\text { study }\end{array}$ & Italy & 30 & $\begin{array}{l}\text { OCD (Obsessive } \\
\text { Compulsive } \\
\text { disorder) }\end{array}$ & $\begin{array}{l}\text { There was a significant increase in the } \\
\text { severity of obsessions and compulsions } \\
\text { from pre quarantine to quarantine period }\end{array}$ \\
\hline $\begin{array}{l}\text { Asmundson } \\
\text { GJ, et al. }{ }^{39}\end{array}$ & $\begin{array}{l}\text { Self-reported } \\
\text { survey }\end{array}$ & $\begin{array}{l}\text { United } \\
\text { States- } \\
\text { Canada }\end{array}$ & 1568 & $\begin{array}{l}500 \text { without } \\
\text { mental illness, } \\
368 \text { with mood } \\
\text { disorder and } \\
700 \text { with anxiety } \\
\text { disorder }\end{array}$ & $\begin{array}{l}\text { Anxiety disorder group had higher } \\
\text { COVID-19 related stressors as compared } \\
\text { to mood disorder and people with no } \\
\text { mental illness, and no difference was } \\
\text { observed between the stress scores of } \\
\text { mood disorder group and no mental } \\
\text { illness group }\end{array}$ \\
\hline $\begin{array}{c}\text { Van } \\
\text { Rheenen, et } \\
\text { al. }^{40}\end{array}$ & $\begin{array}{l}\text { Population } \\
\text { based cross } \\
\text { sectional } \\
\text { study }\end{array}$ & Australia & 4459 & $\begin{array}{l}1292 \text { with } \\
\text { bipolar disorder } \\
\& 3167 \text { with no } \\
\text { known mental } \\
\text { illness }\end{array}$ & $\begin{array}{l}\text { Increased psychological distress in mood } \\
\text { disorder group than in people without } \\
\text { mental illness and these are associated } \\
\text { with maladaptive life style changes } \\
\text { related to COVID-19 in mood disorder } \\
\text { group }\end{array}$ \\
\hline
\end{tabular}




\section{Schizophrenia and COVID-19}

People with schizophrenia may be more susceptible to transmission of COVID-19 due to cognitive impairment, lower awareness of risk and poor infection control practices. $60 \%$ of schizophrenics are chronic smokers, which may increase the risk of disease progression and severe complications from COVID-19. ${ }^{6}$

Elderly population with clinical comorbid condition increases the mortality associated with COVID-19. Majority of the clients with schizophrenia (more than 70\%) have one or more clinical comorbidities like type II Diabetes Mellitus, Hypertension, Chronic Pulmonary and cardiac diseases. In general, schizophrenia and a comorbid medical condition worsen the COVID-19 clinical outcome. ${ }^{7}$

COVID-19 crisis has also created an impact on the psychopathology of patients with existing paranoid psychosis leading to a psychotic phase with paranoid hallucinatory experiences, unrealistic expectations and concerns. ${ }^{8} \mathrm{~A}$ self-reported online survey of outpatients $(N>1400)$ in China with pre-existing psychiatric disorders found that there is a $21 \%$ deterioration related to the pandemic itself. Anxiety, depression, and insomnia were attributed to fear of infections, restrictions on transportation and isolating at home. ${ }^{9}$

Social isolation, unemployment, homelessness, domestic violence, and worsening of physical health are considered as the long-term social effects of COVID-19 and may all these factors particularly affect people with psychosis. Another complicating fact is that usage of high doses of steroids in treating COVID-19 may trigger psychotic symptoms, as steroids are known to cause psychotic symptoms. ${ }^{10}$

A temporal relationship between schizophrenia and viral infections are discussed in several studies earlier. Accordingly, the prevalence of schizophrenia can increase in the subsequent years due to neuronal involvement of coronavirus. ${ }^{11}$ There is evidence for a positive association between the outbreak of COVID-19 and unusual rising of schizophrenia in patients who do not have a previous history of mental illness. ${ }^{12}$

\section{Anxiety, Depression and COVID-I 9}

Bipolar disorder mostly has high comorbidity with physical illnesses, which reduces the immune functioning and increases the risk of SARS COV-2. Also, the current antiviral treatments used for COVID-19 to be used with caution in people with bipolar disorder, because of possible drug interaction between these medications and antidepressants. Possible adverse effects of chloroquine and hydroxychloroquine includes psychosis, mania, mood changes, suicidal ideation and also exacerbation of bipolar disorder. ${ }^{13}$ Suicide is a pressing concern and is likely to increase during pandemic due to social isolation, entrapment and loneliness. ${ }^{14}$

A web based cross-sectional survey of 7236 volunteers in China showed that younger people have a higher prevalence of generalized anxiety disorder and depressive symptoms than older people do during COVID-19 pandemic and health care workers have poor sleep quality compared to other occupational groups during COVID-19. ${ }^{15}$

Obsessions of contamination and compulsive hand washing is increased with this pandemic. Need based hoarding is also increased during pandemic especially when lockdown is announced, which can result in shortage of supplies and agitation in public. The increased anxiety can result in selfmedication with chloroquine, which might be cardio toxic to some people. ${ }^{16}$

\section{Substance Abuse Related Disorders and COVID-19}

Because of the direct challenge to respiratory health, substance abuse disorders may increase the risk of complications due to COVID-19. ${ }^{17}$ People vaping nicotine, opioids and methamphetamine are considered at greater risk of COVID-19 related complications owing to compromised lung functioning among these patients. ${ }^{18}$

Many global pandemics were also associated with negative emotions like anxiety, fear, sadness, irritability, boredom and anger. ${ }^{19}$ These conditions may trigger relapse in abstainers or intensify the consumption in those who are already using it. Withdrawal symptoms may provoke the drug abusers to go outside and increase their risk for COVID-19. ${ }^{20}$

\section{Childhood Psychiatric Disorders and COVID- 19}

The COVID-19 Crisis has resulted in a multifaceted burden on the mental health of children; that is at individual, family and community level. Though this pandemic can hit every child, the children disadvantaged are at a higher risk. ${ }^{21}$ Children with chronic mental illness receiving rehabilitation and other supportive services are deprived of them due to lock down. Moreover, children with intellectual disability are unable to understand the situation and the necessity for restrictions resulting in agitation and increasing anxiety. ${ }^{22}$

Individuals with attention deficit hyperactivity disorder (ADHD) may display more behavioral problems during this pandemic due to many new restrictions imposed on them. ${ }^{22}$ Even the smallest and most common changes can be annoying for children with autism spectrum disorders. COVID-19 has brought an end of routine activities like school, rehabilitation services, various kinds of play and support at activities. ${ }^{23}$

\section{Mental Health of Elderly and COVID-19}

Social isolation, however a key approach to combat 
COVID-19; it is a foremost reason for loneliness especially among elderly. Most of the elderly are not comfortable with use of smartphones and social media during lock down. Cognitive impairment and other problems associated with ageing can make it more challenging for them to track the need for social distancing and repeated hand hygiene. Besides people with already existing psychotic problems are vulnerable to exacerbations during this period. ${ }^{24}$

\section{Challenges to Treatment of PMI during COVID- I9 Pandemic}

There are certain key challenges for psychiatry imposed by COVID-19 pandemic that require urgent attention to ensure mental wellbeing to the community. Handwashing as per recommendation can be difficult as most of the psychiatric patients have poor personal hygiene and may be difficult to follow the regulations due to mental illness itself. Most of the time psychiatric patients might have been admitted to inpatient units for safety concerns to self or others, hence cannot be discharged with self or home quarantine in case of a COVID-19 positive status. ${ }^{25}$ As many outpatient clinics are minimizing face to face service to patients, it delays the discharge process from the inpatient units and results in unavailability of beds for the new patients; exacerbating the acute illness and its consequences. ${ }^{26}$

Mentally ill can be afraid of using a full suit Personal Protective Equipment (PPE) or seeing staff members in PPE, most of the masks have a plastic or metal bit at the nasal end and it can be a safety concern if it goes missing from the patient. Use of PPE might be difficult during use of restraints due to additional safety risk it possesses. Those who already have problems with communication are aggravated by use of facemasks, social distancing and isolation. ${ }^{27}$

\section{Future Directions and Recommendations to Treatment of PMI}

Telepsychiatry can play a pivotal role in providing psychoeducation, coaching, and monitoring of psychotherapeutic interventions during this crisis and later during the stay home period. ${ }^{28}$ Creating a virtual helpline within the hospitals, treatment centers, with the help of multidisciplinary team to deliver real-time support and intermittent enduring behavioral and medical support is beneficial in supporting adolescents and children having any kind of disability during this pandemic situation. ${ }^{30}$ Integration of hospital and other supportive community resources is essential to enhance the psychological preparedness of nations. ${ }^{31}$

Treatment and therapies for substance use and addiction must be strengthened instead of delaying it to evade complications due to substance use and COVID-19 crisis. ${ }^{19}$ Use a kind and reassuring approach with children and provide family time and various leisure activities at home for children with mental health disabilities. ${ }^{29}$ Control the amount of information through media to which these at-risk populations are exposed so that they are not frightened more. $^{19}$

Mitigating adverse effects of social isolation on elderly during this pandemic can be done by health and social care provision, psychological therapies; social facilitation intervention, pet therapy, befriending intervention and leisure/ skill development activities. ${ }^{30}$ Patients to the inpatient unit can be screened on admission and frequently monitored for fever or respiratory infections. All staff must follow the recommended infection control practices to prevent the spread of COVID-19. Whenever possible advice on hand hygiene, use of masks and isolation precautions are necessary for the patients. Ensure proper cleaning and disinfection of all surfaces including door handles, computers, and identification cards. ${ }^{25}$ Developing outreach services for patients with pre-existing mental illnesses can be considered to ensure continuity of care. ${ }^{26}$

\section{Conclusion}

Past tragedies have shown that the amount of mental health implications of a global pandemic can last longer than the pandemic itself. The policy makers, health care system, and the researchers should quicken new ways of meeting the treatment and recovery needs of these populations through measures ranging from enhancing virtual resources to minimize office visits and encouraging use of depot preparations for pre-existing mental illnesses. Recent research evidence suggests that a multi-disciplinary team including psychiatrists, psychologists, psychiatric social workers, psychiatric nurses and other mental health care professionals should be initiated in every catchment area. Hence, the health sector could support the ones with preexisting mental illness and the general population before their mental Health concerns require hospital admission.

Funding: No funding

\section{Ethical Considerations: None}

\section{Conflict of Interest: None}

\section{Reference}

1. WHO Coronavirus Disease (COVID-19). 2020. Dashboard. Accessed from: https://covid19.who.int/?gclid=CjwKCAjwi_b3BRAGEiwAemPNU7y7pqRR01 IMIVVYROQOWSeWfTmz_jjPPfJaGXEf77iXyt29iZ9y4RoChKIQAvD_BwE.

2. United Nations. Policy brief: COVID-19 and the need for action on mental health. 2020. Available from: https:// unsdg.un.org/sites/default/files/2020-05/UN-PolicyBrief-COVID-19-and-mental-health.pdf.

3. Noori S. Mental Health after COVID-19. 2020. Available 
from: https://www.scientificamerican.com/article/ mental-health-after-covid-19/.

4. WHO Fact sheet. Mental disorders. 2019. Available from: https://www.who.int/news-room/fact-sheets/ detail/mental-disorders.

5. Chevance A, Gourion D, Hoertel $N$ et al. Ensuring mental health care during the SARS-CoV-2 epidemic in France: a narrative review. L'encephale, 2020.

6. Kozloff N, Mulsant BH, Stergiopoulos V et al. The COVID-19 global pandemic: implications for people with schizophrenia and related disorders. Schizophrenia Bulletin, 2020.

7. Fonseca L, Diniz E, Mendonca G et al. Schizophrenia and COVID-19: risks and recommendations. Brazilian Journal of Psychiatry 2020; 42(3): 236-238.

8. Fischer M, Coogan AN, Faltraco F et al. COVID-19 paranoia in a patient suffering from schizophrenic psychosis-a case report. Psychiatry Research 2020; 288: 113001.

9. Stein MB. Coronavirus disease 2019 (COVID-19): Psychiatric illness. 2019. Available from: https://www. uptodate.com/contents/coronavirus-disease-2019covid-19-psychiatric-illness.

10. Brown E, Gray R, Monaco SL et al. The potential impact of COVID-19 on psychosis: A rapid review of contemporary epidemic and pandemic research. Schizophrenia Research, 2020.

11. Zandifar A, Badrfam R. COVID-19; considering the prevalence of schizophrenia in the coming decades. Psychiatry Research 2020.

12. Hu W, Su L, Qiao J et al. COVID-19 outbreak increased risk of schizophrenia in aged adults. PsyChinaXiv, 2019.

13. Stefana A, Youngstrom EA, Chen J et al. The COVID-19 pandemic is a crisis and opportunity for bipolar disorder. Bipolar Disord 2020; 22: 641-3.

14. Gunnell D, Appleby L, Arensman E et al. Suicide risk and prevention during the COVID-19 pandemic. The Lancet Psychiatry 2020; 7(6): 468-471.

15. Huang Y, Zhao N. Generalized anxiety disorder, depressive symptoms and sleep quality during COVID-19 outbreak in China: a web-based cross-sectional survey. Psychiatry Research 2020.

16. Banerjee DD. The other side of COVID-19: Impact on obsessive compulsive disorder (OCD) and hoarding. Psychiatry Research 2002; 288: 112966.

17. Volkow ND. Collision of the COVID-19 and addiction epidemics. Annals of Internal Medicine 2020.

18. Khadse PA. Substance use disorders during COVID-19 crisis in developed vs developing world. Annals of Internal Medicine 2020.

19. Ornell F, Schuch JB, Sordi AO et al. "Pandemic fear" and COVID-19: mental health burden and strategies. Brazilian Journal of Psychiatry 2020; 42(3): 232-235.
20. Ornell F, Moura HF, Scherer JN et al. The COVID-19 pandemic and its impact on substance use: implications for prevention and treatment. Psychiatry Research 2020; 13: 113096.

21. Fegert JM, Vitiello B, Plener PL et al. Challenges and burden of the Coronavirus 2019 (COVID-19) pandemic for child and adolescent mental health: a narrative review to highlight clinical and research needs in the acute phase and the long return to normality. Child and Adolescent Psychiatry and Mental Health 2020; 14: 1.

22. Cortese $S$, Asherson P, Sonuga-Barke E et al. ADHD management during the COVID-19 pandemic: guidance from the European ADHD Guidelines Group. The Lancet Child \& Adolescent Health, 2020.

23. Altable M. Child and adult autism spectrum disorder in COVID-19 pandemic. Qeios 2020.

24. Banerjee D. The impact of Covid-19 pandemic on elderly mental health. International Journal of Geriatric Psychiatry 2020.

25. Li L. Challenges and priorities in responding to COVID-19 in inpatient psychiatry. Psychiatric Services 2020.

26. Xiang YT, Zhao YJ, Liu ZH et al. The COVID-19 outbreak and psychiatric hospitals in China: managing challenges through mental health service reform. International Journal of Biological Sciences 2020; 16(10): 1741.

27. Mitchell G, Ford M. Covid-19 crisis has exposed inequalities for mental health and learning disabilities. Nursing times news, 2020. Available from: https:// www.nursingtimes.net/news/coronavirus/covid-19crisis-has-exposed-inequalities-for-mental-health-andlearning-disabilities-03-07-2020/.

28. Papanikolaou K, Pehlivanidis A. COVID-19 Pandemic and social distancing in adult ADHD: It is a marathon race, not a sprint. Covid Perspect Res \& Rev 2020; 01(01): 1-2.

29. Smile SC. Supporting children with autism spectrum disorder in the face of the COVID-19 pandemic. CMAJ 2020; 192(21): E587.

30. Rout N. Risks to the elderly during the coronavirus (COVID-19) pandemic 2019-2020. Journal of Geriatric Care and Research 2020; 7(1): 27-28.

31. Shigemura J, Ursano RJ, Morganstein JC et al. Public responses to the novel 2019 coronavirus (2019-nCoV) in Japan: Mental health consequences and target populations. Psychiatry and Clinical Neurosciences 2020; 74(4): 281.

32. Rajkumar RP. COVID-19 and mental health: A review of the existing literature. Asian Journal of Psychiatry 2020.

33. Jessenia MG, Daniel HH, Adislen GH et al. Beyond the Respiratory System: A Case Report Highlighting the Impact of COVID-19 in Mental Illness and Its Physical Consequences. The Journal of Clinical Psychiatry 2020; 81(4): 20113465.

34. Hao F, Tan W, Jiang $L$ et al. Do psychiatric patients 
experience more psychiatric symptoms during COVID-19 pandemic and lockdown? A case-control study with service and research implications for immunopsychiatry. Brain, Behavior, and Immunity, 2020.

35. Schützwohl M, Mergel E. Social participation, inclusion and mental well-being following SARS-CoV-2 related lockdown restrictions in adults with and without mental disorders. Results from a follow-up study in Germany. Psychiatr Prax 2020; 47(6): 308-318.

36. Liu $X$, Lin $H$, Jiang $H$ et al. Clinical characteristics of hospitalized patients with schizophrenia who were suspected to have coronavirus disease (COVID-19) in Hubei Province, China. General Psychiatry 2020; 33: e100222.

37. Cranshaw T, Harikumar T. COVID-19 Infection May Cause Clozapine Intoxication: Case Report and Discussion. Schizophrenia Bulletin, 2020.

38. Davide $P$, Andrea $P$, Martina $O$ et al. The impact of the COVID-19 pandemic on patients with OCD: effects of contamination symptoms and remission state before the quarantine in a preliminary naturalistic study. Psychiatry Research 2020.

39. Asmundson GJ, Paluszek MM, Landry CA et al. Do Pre-existing Anxiety-Related and Mood Disorders Differentially Impact COVID-19 Stress Responses and Coping? Journal of Anxiety Disorders 2020.

40. Van Rheenen TE, Meyer D, Neill E et al. Mental health status of individuals with a mood-disorder during the COVID-19 Pandemic in Australia: Initial Results from the COLLATE Project: COVID-19 and mood disorders. Journal of Affective Disorders 2020. 